\title{
Smaller grants for more Canadians?
}

Sir - We often hear that the major problem with scientific and medical research in Canada is the insufficient level of government funding. The biggest sources of research funding for universities are the three federal research funding councils, the Natural Sciences and Engineering Research Council (NSERC), the Medical Research Council (MRC) and the Social Sciences and Humanities Research Council (SSHRC).

Are these agencies underfunded? According to the admission of the councils themselves, many researchers who receive evaluations of excellence do not receive funding because the granting agencies run out of money before getting to their particular proposal. Deciding which of two excellent proposals will or will not be funded is never easy. Committees must therefore make decisions on the basis of differences that are largely irrelevant to the potential contribution of a particular proposed research project.

There are two possible solutions. The first would be to make it possible for all excellent programmes to get funding at the level requested by the applicants. This is clearly impossible in the current political state of restraint. As the pie is limited, perhaps we should be asking whether we are managing the pie and cutting the pieces fairly, to which the answer is a resounding no.

According to the latest report from MRC, it approves about 600 new grants a year, but is turning down another 350 proposals that meet its standards of excellence. The question then boils down to the following: If you have $600+350=950$ proposals a year which satisfy MRC standards of excellence, what stops MRC from funding them all? In a zero-sum game, of course, this will mean that the average grant size should drop to $600 / 950=63 \%$ of its present average. But then there would be no excellent researchers without funds.

A reduction to $63 \%$ may appear severe to the already funded researcher. But for the researcher who gets nothing now, that amount would be considered a great boon. Tough as it appears, this simple change would allow all "excellent" researchers to be funded and to implement at least their main research priorities. Furthermore, because more scarcity will undoubtedly result in a much more careful setting of priorities, the overall quality of research is likely to increase, not decrease, and all "excellent" proposals will be funded on at least some level.

This is the first thing MRC (and likewise NSERC and SSHRC), should do before asking the government for more money. Those at present involved in the campaign for more money for the funding councils should first of all ask the councils' presidents what are the guarantees that this "extra" money will be used to fund those at present unfunded, instead of being distributed among those who are already well funded. The present structure of the funding councils provides no such guarantees.

The existing composition of funding councils is such that the key members of the grant selection panels are grant recipients themselves. All assurances to the contrary notwithstanding, this constitutes a fundamental conflict of interest. It is not then surprising that the distribution of research grants follows the infamous Matthew principle ("the rich get richer, the poor get poorer"). In other words, those who decide how to cut the pie are the same people who want to ensure they get their own piece first.

This is where the most urgent change is needed. We need restoration of the fundamental 'arm's length' principle that those who distribute the research funds should not themselves be the beneficiaries of the funding system (grant recipients). This would be a first step towards more productive and efficient use of Canadian research dollars. Only after that will we be able to decide if we really have genuine research underfunding, or rather a case of poor management of available resources.

Alexander A. Berezin

Department of Engineering Physics,

McMaster University,

Hamilton, Ontario, Canada, L8S $4 L 7$

e-mail:berezin@mcmail.cis.mcmaster.ca

Richard Gordon

Department of Radiology,

University of Manitoba,

Room ON104,

Health Sciences Centre,

820 Sherbrook Street

Winnipeg, MB R3A 1R9, Canada

\section{Brussels backs research}

Sir - I should like to comment on your leading article "Science and technology deserve better from Brussels" (Nature 385, 661 ; 1997) which gives an account of the European Commission's recent proposals for the European Union's fifth Framework programme for research.

You state that the commission has not achieved the concentration on a few areas which it presented several months ago as its objective. In fact, what the commission seems actually to have attempted, with some success, is to strike a balance between concentration on a selected number of objectives essential for a significant impact in economic and social terms and support for sufficient collaboration in some fundamental fields to ensure the continued development of European scientific and technological excellence. This double objective explains the presence in the proposal of a larger number of topics than there might otherwise have been.

Will the steps towards concentration taken so far be translated into reality? The European Union's decision-making system for research, which involves the unanimous adoption of the Framework programme by the member states jointly with the European Parliament, is far from ideal. Having been commissioner for research, I know how difficult it is to avoid spreading our research efforts over a multiplicity of subjects corresponding to the preferences of the member states and various sectoral interests.

The present research commissioner, Edith Cresson, appears to be firmly resolved to defend the principle of real concentration. Stating, as you do, that the fight is already lost, seems to me to be, at the very least, premature. It is not unreasonable to hope that the Framework programme, when it is finally adopted, will correspond to the ideas already presented. The commission has already announced that it will set up an appropriate management system for its implementation. Saying, as you do, that the Framework programme will be impossible to manage is inappropriate.

Finally, your explanation of the root cause of the supposed weakness of the commission's proposals shocked me. I am astonished that you should call into question the commissioner's interest in research. The significant role which, according to your own account, the fifth Framework programme assigns to fundamental research bears witness to the opposite opinion, and shows that Cresson has fully appreciated the importance for society of the pursuit of knowledge.

Antonio Ruberti

Camera dei Deputati,

Rome, Italy

corres@nature.com Letters submitted for Correspondence may be e-mailed to corres@nature.com. Do not send items intended for any other section by e-mail unless requested to do so. 